\title{
Comparison of Life Satisfaction in Patients with Congenital Heart
} Diseases

\author{
Behnaz Farzinfar (iD ${ }^{1}$, Saeed Abtahi (iD) ${ }^{1,}$ and Mehrdad Sadeghi Ordoubadi ${ }^{2}$ \\ ${ }^{1}$ Department of Pediatric Cardiology, Mashhad Branch, Islamic Azad University, Mashhad, Iran \\ ${ }^{2}$ Department of Cardiology, Mashhad University of Medical Sciences, Mashhad, Iran \\ "Corresponding author: Department of Pediatric Cardiology, Mashhad Branch, Islamic Azad University, Mashhad, Iran. Email: sabtahimd@yahoo.com \\ Received 2018 December 20; Revised 2019 April 07; Accepted 2019 April 14.
}

\begin{abstract}
Background: Congenital heart diseases (CHD) constitute a wide range of heart abnormalities. Major advances in surgical treatments have led to a rapidly growing number of surviving individuals. Living well to most people is as important as living longer. Currently, there are few studies on this group of patients regarding their satisfaction with life.

Objectives: This study attempts to compare satisfaction with life among CHD patients.

Methods: In this cross-sectional study, patients with cyanotic and acyanotic CHD were enrolled. Satisfaction with Life was assessed using SWLS.

Results: Eighty patients (52.05\% females) with cyanotic (21.3\%) and acyanotic CHD were enrolled. The patients with cyanotic CHD were as satisfied with their life as the patients with acyanotic CHD. There were no statistical significant differences between cyanotic and acyanotic patients regarding satisfaction with life. Younger age was associated with a higher degree of satisfaction with life. Women and patients with a history of corrective cardiac surgery were more satisfied with their life. Correlations between satisfaction with life and age and sex were not statistically significant.

Conclusions: We found that the patients with cyanotic CHD were as satisfied with their life as acyanotic patients. The results of our study indicate that life satisfaction was not associated with age, sex, and the history of corrective cardiac surgery.
\end{abstract}

Keywords: Congenital Heart Disease, Life Satisfaction, Cyanotic, Acyanotic

\section{Background}

Congenital heart diseases (CHD) are abnormalities or defects in heart chambers or vessels, which appear at birth with a prevalence of 4 per $1000(1,2)$. The CHDs vary in the extent of severity, and the type of abnormality influences the patients' capacity of performing normal daily activities $(3,4)$. With the advancements in the surgical treatment of congenital heart malformations, the life expectancy of these patients is increasing and currently more than $90 \%$ of cases reach adulthood (5-7). The disease per se is not always the main issue for these patients since issues concerning life satisfaction are often predominate. Life satisfaction is largely stable across the lifespan and it is defined as an individual's contentment with life $(8,9)$. It is frequently referred to as the degree of an individual's subjective consideration if their goals and achievements have been accomplished (10). The aim of this study was to compare life satisfaction in the patients with CHD. Although various factors, such as finances and marital status, are related to satisfaction with life, we evaluated it as a whole (11). Any correla- tions between satisfaction with life and age, sex and, having a previously corrective cardiac surgery would also be noted.

\section{Methods}

\subsection{Patient Selection}

The current study was performed on the patients of our outpatient CHD clinic in Mashhad in 2018. The patients with cyanotic and acyanotic CHD between the age of 15 and 35 years were eligible to take part in this study. The institutional review board approved the study protocol and written informed consent was obtained from all patients before the enrollment.

\subsection{Life Satisfaction}

Satisfaction with life was assessed using the satisfaction with life scale (SWLS), which is a reliable and validated self-report questionnaire. The SWLS comprises 5 items, which are as follows: (1) 'In most ways my life is close to my 
ideal'; (2) ‘My life condition is very good'; (3) ‘I am satisfied with my life', (4)'I have got the important things, which I want in the life' and (5) 'If I had a new life, I would enjoy it just as I do now'. All items are answered on a Likert scale (1: strongly disagree, 2: disagree, 3: incomplete disagree, 4: not sure, 5: incomplete agree, 6: agree, and 7: strongly agree) (12). The respondents were asked to indicate one out of 7 answers being the most consistent with their status. Summation of complete item responses provides a score that ranges from 5 to 35 . A total score of 20 - 24 was considered average satisfaction with life; scores between 25 - 29 were considered high satisfaction with life and scores between 15 - 19 were slightly below average, while scores between 5 - 14 and 30 - 35 represented extremely low or high satisfaction with life, respectively.

The Persian version of SWLS was employed in the current study. Bayani et al. have examined the validity and reliability of the Persian version of SWLS in a study in which the test-retest reliability was calculated at 0.69 at the significance level of 0.001 and Cronbach's alpha coefficient was estimated to be $0.83(13)$.

\subsection{Statistical Analysis}

The SPSS for Windows version 20.0 was used in this study. To analyze group differences, Fisher's exact tests for categorical data were performed. Statistical significance was considered to be at a $\mathrm{P}<0.05$.

\section{Results}

In this study, 80 patients with CHD were evaluated, 17 (21.3\%) had cyanotic CHD and 63 (78.8\%) had non-cyanotic CHD. Forty-two (52.5\%) of the patients were female and 38 $(47.5 \%)$ were male. The youngest patient included in the study was aged 15 years and the oldest was aged 35 years; the mean age was 27.32 years old. Forty-one (51.3\%) had previously corrective cardiac surgery (Table 1 ).

The diagnoses of CHD in both cyanotic and acyanotic groups are shown in Figure 1.

Females and males differed in terms of the mean overall SWLS scores; females were more satisfied with their lives; however, this was not statistically significant (Table 2). Satisfaction with life values in the group of younger patients was higher than in the older group; however, this was not statistically significant (Table 2). Satisfaction with life values in the group of the patients with previous corrective cardiac surgery was higher than in the group without surgery; however, this was not statistically significant (Table 2).

The results of the comparison of SWLS values in terms of disease category (cyanotic/acyanotic) are presented in

\begin{tabular}{|c|c|}
\hline Variable & No. (\%) \\
\hline \multicolumn{2}{|l|}{ Sex } \\
\hline Male & $38(47.5)$ \\
\hline Female & $42(52.5)$ \\
\hline \multicolumn{2}{|l|}{ Age } \\
\hline $15-27$ & $41(51.2)$ \\
\hline $28-35$ & $39(48.8)$ \\
\hline \multicolumn{2}{|l|}{ Cyanotic CHD } \\
\hline- & $63(78.8)$ \\
\hline+ & $17(21.2)$ \\
\hline \multicolumn{2}{|c|}{ Corrective cardiac surgery } \\
\hline- & $39(48.8)$ \\
\hline+ & $41(51.2)$ \\
\hline
\end{tabular}

Table 2. The SWLS value of the cyanotic group was not different from the acyanotic group; however, this was not statistically significant. The relationship between satisfaction with life and age, sex, and having corrective cardiac surgery was not statistically significant. Satisfaction with life in terms of age and sex in the cyanotic group was calculated and no significant relationship was found.

\section{Discussion}

Advances in medical and surgical treatments have led to a considerable decrease in mortality among patients with CHD; therefore, the vast majority of these patients reach adulthood (14-19). Thus researches should now focus on the outcomes other than death. As far as we know, similar articles have examined the quality of life in this group of patients and this is the first study that has compared life satisfaction among CHD patients using a validated scale (12).

Eighty patients with CHD were evaluated in our study. When the satisfaction with life values of the patients with CHD was evaluated, it was observed that these patients had the same values of satisfaction with life in the presence of cyanotic CHD. Moons et al. claimed that the severity of CHD is minimally associated with perceived health and the quality of life (20). In another study conducted by Kahr et al. it was shown that the quality of life was impaired in patients with moderate and complex CHDs. However, the quality of life in patients with simple CHD was normal (21). Holbein et al. examined the quality of life in CHD patients and concluded that patients with a Fontan circulation had a lower quality life compared with ASD/VSD patients (22).

Ternestedt et al. reported that the group of patients with TOF rated their quality of life higher than the group of patients with ASD. Compared with patients with ASD, fewer patients with TOF believed that their life was affected by the 


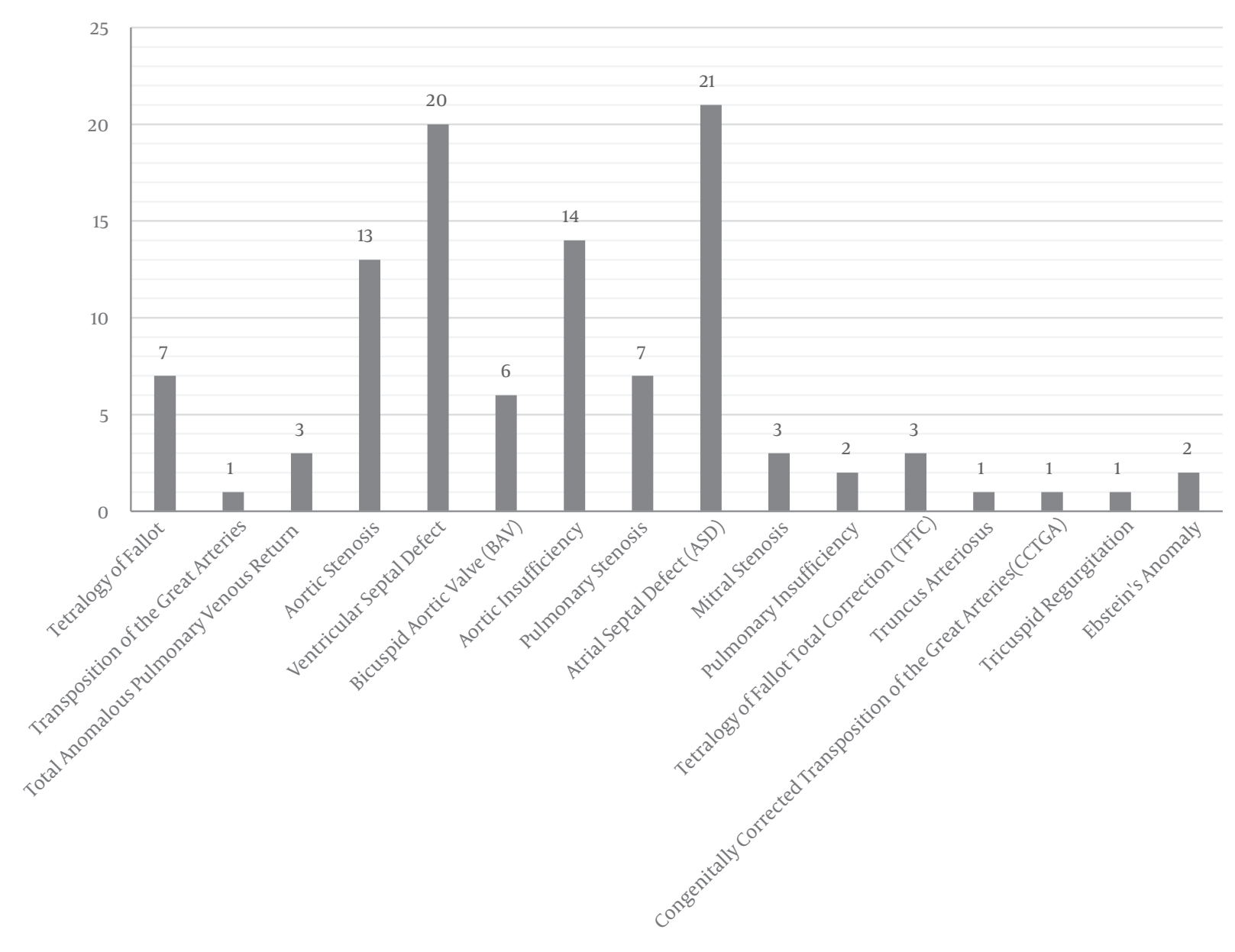

Figure 1. Types of congenital heart diseases in the studied patients

disease. They concluded that mild heart diseases, may affect later life quality and the severity of the heart disease is not necessarily coherent with estimated quality of life (15).

No statistical significant association was observed between age and satisfaction with life in the current study. Reiner et al. declared that young patients with CHD reported their health-related quality of life as high as their healthy peers (23).

As Hunter and Swan declared, in contrast to most patients where illness is a factor of advancing age, the majorities of CHD patients have lived their entire lives with their condition and will have undergone at least one; if not multiple interventions by the time they reach adulthood (24). Boukovala et al. showed that adolescents and adults with CHD had a better physical health-related quality of life following surgery and catheter intervention compared with other treatment options (25).

Our study showed that life satisfaction was higher among patients with a history of corrective cardiac surgery; however, no statistical significance was observed. Ladak et al. indicated that CHD surgical patients had a lower health-related quality of life in comparison to their healthy counterparts (26).

In another study conducted by Kamphuis et al. similar findings were reported; health-related quality of life was poorer in patients with the history of complex CHD surgery compared with the general population (27).

Pragt et al. exhibited that the quality of life in CHD patients with prosthetic valve was lower than the general population (28). Since no statistical significance was observed in the current study, further carefully designed studies with a greater sample size are necessary to demonstrate any potential relationship between age, sex, type of disease, a history of corrective cardiac surgery and satisfaction with life in CHD patients. 


\begin{tabular}{|c|c|c|c|c|c|c|c|c|}
\hline \multirow{2}{*}{ Parameters } & \multicolumn{7}{|c|}{ Life Satisfaction Status } & \multirow{2}{*}{ PValue } \\
\hline & $\begin{array}{l}\text { Extremely } \\
\text { Satisfied }\end{array}$ & Satisfied & $\begin{array}{l}\text { Slightly } \\
\text { Satisfied }\end{array}$ & Neutral & $\begin{array}{c}\text { Slightly } \\
\text { Dissatisfied }\end{array}$ & Dissatisfied & $\begin{array}{c}\text { Extremely } \\
\text { Dissatisfied }\end{array}$ & \\
\hline Type of CHD & & & & & & & & 0.194 \\
\hline Acyanotic & $4(6.3)$ & $17(27)$ & $16(25.4)$ & $6(9.5)$ & $11(17.5)$ & $5(7.9)$ & $4(6.3)$ & \\
\hline Cyanotic & $3(17.6)$ & $0(0)$ & $6(35.3)$ & $2(11.8)$ & $4(23.5)$ & $2(11.8)$ & $0(0)$ & \\
\hline Age & & & & & & & & 0.417 \\
\hline $15-27$ & $4(9.8)$ & $6(14.6)$ & $14(34.1)$ & $5(12.2)$ & $7(17.1)$ & $2(4.9)$ & $3(7.3)$ & \\
\hline $28-35$ & $3(7.7)$ & $11(28.2)$ & $8(20.5)$ & $3(7.7)$ & $8(20.5)$ & $5(12.8)$ & $1(2.6)$ & \\
\hline Sex & & & & & & & & 0.925 \\
\hline Male & $3(7.9)$ & $8(21.1)$ & $9(23.7)$ & $4(10.5)$ & $7(18.4)$ & $4(10.5)$ & $3(7.9)$ & \\
\hline Female & $4(9.5)$ & $9(21.4)$ & $13(31)$ & $4(9.5)$ & $8(19)$ & $3(7.1)$ & $1(2.4)$ & \\
\hline Corrective cardiac surgery & & & & & & & & 0.730 \\
\hline- & $2(5.1)$ & $8(20.5)$ & $11(28.2)$ & $3(7.7)$ & $10(25.6)$ & $3(7.7)$ & $2(5.1)$ & \\
\hline+ & $5(12.2)$ & $9(22)$ & $11(26.8)$ & $5(12.2)$ & $5(12.2)$ & $4(9.8)$ & $2(4.9)$ & \\
\hline
\end{tabular}

${ }^{\mathrm{a}}$ Values are expressed as No. (\%).

\subsection{Conclusion}

In conclusion, we found that life satisfaction in patients with cyanotic congenital heart disease and acyanotic congenital heart disease is not different and this association was not statistically significant. It was also concluded that age, sex, and the history of corrective cardiac surgery do not affect satisfaction with life in patients with congenital heart disease.

\section{Acknowledgments}

We would like to thank all participants for their contribution to this research.

\section{Footnotes}

Authors' Contribution: Study concept and design: Saeed Abtahi and Mehrdad Sadeghi Ordoubadi; acquisition of data: Mehrdad Sadeghi Ordoubadi; analysis and interpretation of data: Behnaz Farzinfar and Saeed Abtahi; drafting of the manuscript: Behnaz Farzinfar; critical revision of the manuscript for important intellectual content: Mehrdad Sadeghi Ordoubadi and Saeed Abtahi; statistical analysis: Behnaz Farzinfar; administrative, technical, and material support: Saeed Abtahi and Mehrdad Sadeghi Ordoubadi; study supervision: Saeed Abtahi.

Conflict of Interests: The authors declare they have no conflict of interest.

Ethical Approval: The Institutional Review Board approved the study protocol (IR.MUMS.REC.1397.239).

Funding/Support: This study was supported by IAUM.
Patient Consent: The written informed consent was obtained from all patients before the enrollment.

\section{References}

1. Hoffman JI, Kaplan S. The incidence of congenital heart disease. J Am Coll Cardiol. 2002;39(12):1890-900. [PubMed: 12084585].

2. Bruneau BG. The developmental genetics of congenital heart disease. Nature. 2008;451(7181):943-8. doi: 10.1038/nature06801. [PubMed: 18288184].

3. Wren C, O'Sullivan JJ. Survival with congenital heart disease and need for follow up in adult life. Heart. 2001;85(4):438-43. [PubMed: 11250973]. [PubMed Central: PMC1729699].

4. Grant H, Dweck CS. Clarifying achievement goals and their impact. J Pers Soc Psychol. 2003;85(3):541-53. doi: 10.1037/0022-3514.85.3.541. [PubMed: 14498789].

5. Harrison JL, Silversides CK, Oechslin EN, Kovacs AH. Healthcare needs of adults with congenital heart disease: Study of the patient perspective. J Cardiovasc Nurs. 2011;26(6):497-503. doi: 10.1097/JCN.0b013e31820984c9. [PubMed: 21372735].

6. Moons P, Bovijn L, Budts W, Belmans A, Gewillig M. Temporal trends in survival to adulthood among patients born with congenital heart disease from 1970 to 1992 in Belgium. Circulation. 2010;122(22):226472. doi: 10.1161/CIRCULATIONAHA.110.946343. [PubMed: 21098444].

7. Gatzoulis MA. Adult congenital heart disease: education, education, education. Nat Clin Pract Cardiovasc Med. 2006;3(1):2-3. doi: 10.1038/ncpcardio0382. [PubMed: 16391593].

8. Baird BM, Lucas RE, Donnellan MB. Life satisfaction across the lifespan: Findings from two nationally representative panel studies. Soc Indic Res. 2010;99(2):183-203. doi:10.1007/s11205-010-9584-9. [PubMed: 21113322]. [PubMed Central: PMC2990956].

9. Lucas RE, Donnellan MB. How stable is happiness? Using the STARTS model to estimate the stability of life satisfaction.J Res Pers. 2007;41(5):1091-8. doi: 10.1016/j.jrp.2006.11.005. [PubMed: 18836511] [PubMed Central: PMC2083650].

10. Johnson W, Krueger RF. How money buys happiness: Genetic and environmental processes linking finances and life satisfaction. $J$ Pers Soc Psychol. 2006;90(4):680-91. doi: 10.1037/0022-3514.90.4.680. [PubMed: 16649863]. 
11. Zhu X, Wang K, Chen L, Cao A, Chen Q, Li J, et al. Together means more happiness: Relationship status moderates the association between brain structure and life satisfaction. Neuroscience. 2018;384:406-16. doi:10.1016/j.neuroscience.2018.05.018. [PubMed: 29792905].

12. Diener E, Emmons RA, Larsen RJ, Griffin S. The satisfaction with life scale. J Pers Assess. 1985;49(1):71-5. doi: 10.1207/s15327752jpa4901_13. [PubMed: 16367493].

13. Bayani AA, Koocheky AM, Goodarzi H. [The reliability and validity of the satisfaction with life scale]. J Dev Psychol. 2007;3(11):259-65. Persian.

14. Warnes CA, Liberthson R, Danielson GK, Dore A, Harris L, Hoffman JI, et al. Task force 1 : The changing profile of congenital heart disease in adult life. J Am Coll Cardiol. 2001;37(5):1170-5. [PubMed: 11300418].

15. Ternestedt BM, Wall K, Oddsson H, Riesenfeld T, Groth I, Schollin J. Quality of life 20 and 30 years after surgery in patients operated on for tetralogy of Fallot and for atrial septal defect. Pediatr Cardiol. 2001;22(2):128-32. doi: 10.1007/s002460010178. [PubMed: 11178668].

16. Hannoush $\mathrm{H}$, Tamim H, Younes H, Arnaout S, Gharzeddine W, Dakik H, et al. Patterns of congenital heart disease in unoperated adults: A 20year experience in a developing country. Clin Cardiol. 2004;27(4):23640. [PubMed: 15119701].

17. Giamberti A, Varrica A, Pome G, Micheletti A, Negura D, Ranucci M, et al. The care for adults with congenital heart disease: Organization and function of a grown-up congenital heart disease unit. Eur Heart J Suppl. 2016;18(suppl E):E15-8. doi:10.1093/eurheartj/suw011.

18. Amaral FT, Manso PH, Schmidt A, Sgarbieri RN, Vicente WV, Carbone Junior $\mathrm{C}$, et al. Recommendations for starting a grown up congenital heart disease (GUCH) unit. Rev Bras Cir Cardiovasc. 2015;30(3):3739. doi: 10.5935/1678-9741.20150037. [PubMed: 26313729]. [PubMed Central: PMC4541785]

19. Gilboa SM, Salemi JL, Nembhard WN, Fixler DE, Correa A. Mortality resulting from congenital heart disease among children and adults in the United States, 1999 to 2006. Circulation. 2010;122(22):2254-63. doi: 10.1161/CIRCULATIONAHA.110.947002. [PubMed: 21098447]. [PubMed Central: PMC4911018].

20. Moons P, Van Deyk K, De Geest S, Gewillig M, Budts W. Is the severity of congenital heart disease associated with the quality of life and perceived health of adult patients? Heart. 2005;91(9):1193-8. doi: 10.1136/hrt.2004.042234. [PubMed: 16103557]. [PubMed Central: PMC1769070].

21. Kahr PC, Radke RM, Orwat S, Baumgartner H, Diller GP. Analysis of associations between congenital heart defect complexity and health-related quality of life using a meta-analytic strategy. Int $J$ Cardiol. 2015;199:197-203. doi: 10.1016/j.ijcard.2015.07.045. [PubMed: 26204568].

22. Holbein CE, Fogleman ND, Hommel K, Apers S, Rassart J, Moons P, et al. A multinational observational investigation of illness perceptions and quality of life among patients with a Fontan circulation. Congenit Heart Dis. 2018;13(3):392-400. doi:10.1111/chd.12583. [PubMed: 29457362]. [PubMed Central: PMC5993574].

23. Reiner B, Oberhoffer R, Ewert P, Muller J. Quality of life in young people with congenital heart disease is better than expected. Arch Dis Child. 2019;104(2):124-8. doi: 10.1136/archdischild-2017-314211. [PubMed: 29599167].

24. Hunter AL, Swan L. Quality of life in adults living with congenital heart disease: Beyond morbidity and mortality. J Thorac Dis. 2016;8(12):E1632-6. doi: 10.21037/jtd.2016.12.16. [PubMed: 28149600]. [PubMed Central: PMC5227241].

25. Boukovala M, Müller J, Ewert P, Hager A. Effects of congenital heart disease treatmenton quality of life. Am J Cardiol. 2019;123(7):1163-8. doi: 10.1016/j.amjcard.2018.12.048.

26. Ladak LA, Hasan BS, Gullick J, Gallagher R. Health-related quality of life in congenital heart disease surgery in children and young adults: A systematic review and meta-analysis. Arch Dis Child. 2019;104(4):340-7. doi: 10.1136/archdischild-2017-313653. [PubMed: 29572215].

27. Kamphuis M, Ottenkamp J, Vliegen HW, Vogels T, Zwinderman KH, Kamphuis RP, et al. Health related quality of life and health status in adult survivors with previously operated complex congenital heart disease. Heart. 2002;87(4):356-62. [PubMed: 11907011]. [PubMed Central: PMC1767074]

28. Pragt H, Pieper PG, van Slooten YJ, Freling HG, van Dijk APJ, Sieswerda GTJ, et al. Quality of life among patients with congenital heart disease after valve replacement. Semin Thorac Cardiovasc Surg. 2019. doi: 10.1053/j.semtcvs.2019.02.002. [PubMed: 30731194]. 